\title{
Co-production of butyrate methyl ester and triacetylglycerol from tributyrin and methyl acetate
}

\author{
Ezio Battistel $^{\mathrm{a}, *}$, Chiara Calaprice $^{\mathrm{b}}$, Enrico Gualdi $^{\mathrm{c}}$, Elena Rebesco $^{\mathrm{d}}$, Elisabetta Maria Usai ${ }^{\mathrm{e}}$ \\ a Eni S.p.A., Research Center for Non-Conventional Energies, Istituto Eni Donegani, via Fauser 4, 28100 Novara, Italy \\ b Stage at Istituto Eni Donegani, Novara, from Materials Engineering Department, University of Alessandria, Italy \\ ' Stage at Istituto Eni Donegani, Novara, from Chemistry Department, University of Modena, Italy \\ d Eni S.p.A., RE'M Division Research Center, via F. Maritano 26, 20097 San Donato Milanese, Milano, Italy \\ e Department of Chemical Sciences, University of Cagliari, Cittadella Universitaria, S.S. 554 Bivio per Sestu, 09042 Monserrato (CA), Italy
}

\section{A R T I C L E I N F O}

\section{Article history:}

Received 15 September 2010

Received in revised form

23 December 2010

Accepted 27 December 2010

Available online 4 January 2011

\section{Keywords:}

Interesterification

Ester exchange

Fatty acid methyl esters

Biodiesel

Synthesis of glycerol triacetate

\begin{abstract}
A B S T R A C T
The simultaneous synthesis of butyric acid methyl ester, the shortest component of the FAME (fatty acid methyl esters) family, and glycerol triacetate (TAG) from glycerol tributyrate (tributyrin) and methyl acetate was studied as a function of several reaction parameters, such as type of catalyst, temperature and products distribution. The reaction is an interesterification, a multistep consecutive ester interchange catalyzed by either acid or base catalyst. Under optimized conditions, a complete tributyrin conversion and an almost quantitative butyric acid methyl ester accumulation were achieved. The other reaction product, TAG, formed by the complete acetylation of the glycerol moiety, reached almost 70\% yield, whereas the mono- and di-acetylated intermediates accumulated in the order of 5-8\% and $24-27 \%$, respectively. Similar final conversions and products yields were obtained with either acid or base homogeneous catalysts, suggesting that the final products mixture did not depend on the type of catalysis but might be limited by equilibrium conditions. In spite of similar final yields, base catalysis needed shorter reaction times (minutes instead of hours) and lower temperature $\left(60^{\circ} \mathrm{C}\right.$ instead of $130^{\circ} \mathrm{C}$ ) with respect to the best acid catalyst. On the other hand, unlike heterogeneous basic catalysts, which showed low activity, a heterogeneous acid catalyst almost as active as the homogenous counterpart was found.
\end{abstract}

(C) 2011 Elsevier B.V. All rights reserved.

\section{Introduction}

The increase in biodiesel (fatty acids methyl esters, FAME) production as renewable fuel has been accompanied by a concurrent increase in the availability of its main co-product, glycerol. The procedure to reach the high degree of purification needed for most commercial applications is difficult and expensive, thus glycerol exploitation as high grade commodity is an important aspect for improving the production process of biodiesel. A promising possibility is the development of technologies that can transform glycerol into compounds suitable to be mixed with biodiesel to improve low temperature and combustion properties [1,2]. An advantage of using glycerol derivatives in fuels is that, as a biocomponent, it could be included in the renewable energy sources category and help to meet EU targets on transportation fossil fuels savings.

Several oxygenated compounds including glycerol carbonates [3], ethers [4] and acetals [5] were proved to successfully enhance fuel properties such as the reduction of viscosity, cloud point and

\footnotetext{
* Corresponding author. Tel.: +39 0321 447444; fax: +39 0321447241.

E-mail address: ezio.battistel@eni.com (E. Battistel).
}

particulate matter emission in diesel and biodiesel blends. A particular class of oxygenated derivatives is that of glycerol esters composed by short chain organic acids such as, for example, acetic acid [2].

In fact, glycerol triacetate (TAG, triacetin) can be added to biodiesel (FAME) without major alteration of the fuel properties [6] and even to gasoline with improvement of the octane parameters [2].

Several routes have been developed to synthesize glycerol organic esters. The direct esterification with organic acids (such as acetic acid) in the presence of acid catalysts (including sulphonic resin and zeolites) is one of the most used methodologies [7,8]. All these approaches are based on the availability of pure glycerol, which has to be independently isolated and purified from the FAME synthesis, a step that, actually, is a common side route of FAME industrial production. In fact, a typical batch or semi-continuous process includes glycerine separation and purification, followed by elimination of the excess methanol used for the initial FAME synthesis. Consequently, FAME and glycerol derivative syntheses are performed in two independent and consecutive steps.

A possible alternative to these conventional processes is the simultaneous co-production of FAME and glycerol oxygenated compounds in the same one-pot reaction, making the glycerin iso- 


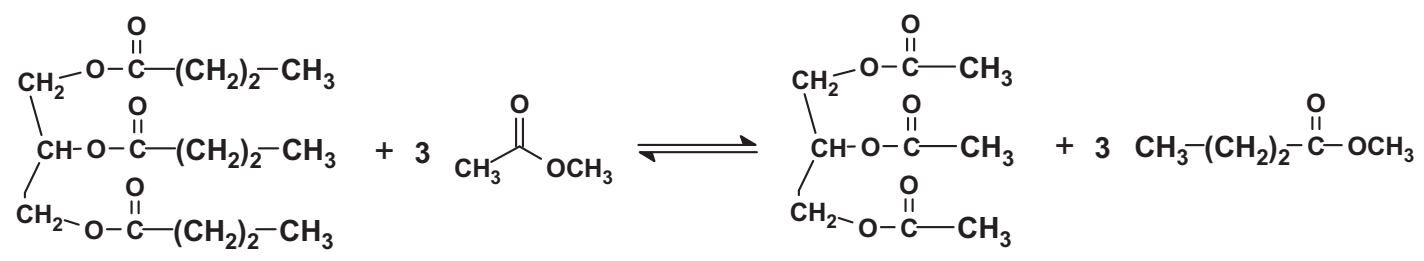

Fig. 1. Overall reaction between tributyrin and methyl acetate to triacetyl glycerol (triacetin) and butyrate methyl ester.

lation and purification steps unnecessary [9]. The simultaneous double synthesis of FAME and glycerol derivatives using vegetable oils as starting material has been carried out by using double groupdonor agents, such as methyl or ethyl acetate. These reagents match the concurrent chemical need of an alcohol, necessary for the esterification of the triglyceride fatty acid, and of an acid, necessary for the esterification of glycerol hydroxyl group(s). The reaction, schematically presented in Fig. 1 in the case of tributyrin as starting triglyceride, ideally yields a mixture of FAME and triacetin (59\% and $41 \%(\mathrm{w} / \mathrm{w})$, respectively, if the reaction goes to completion), without co-production of glycerol and intermediates.

When triglycerides containing long chain fatty acids are used, the final mixture could be used directly as component in diesel and biodiesel blends, without further treatment. This can be clearly concluded from the data presented in Table 1, where the fuel properties of diesel/FAME and diesel/FAME-TAG blends are compared with the pure base diesel. As it can be seen, the addition of $10 \mathrm{vol} \%$ FAME to a standard base diesel improved somewhat the fuel properties of the base diesel by increasing slightly cetane parameters and flash point. The mixture FAME/TAG at $10 \%$ level did not further induce any major change with respect to FAME alone. In particular, distillation-95\% temperature and viscosity were slightly lowered and closer to the base diesel values.

Transesterification with methyl acetate has been studied to some extent by using enzymes as catalysts $[10,11]$. It was found that vegetable oils from different sources can be converted almost quantitatively to the corresponding FAME (yields $>90 \%$ ) in the presence of methyl acetate. Suitable enzyme catalysts are lipases, mainly bacterial, which are able to function in organic media and, after immobilization, to withstand recycling without significant loss of activity. Although the yield of FAME is almost quantitative, no detailed analysis was carried on the compositions of the final products mixture, nor on the yield of triacetin, the end product of the multi-acylation step. The enzyme catalyzed reactions have the advantages of the mild reaction conditions (temperature as high as $40-60^{\circ} \mathrm{C}$, no catalyst purification, and possible catalyst recycling). However, they suffer from some important drawbacks such as long reaction times (40-60 h), sensitivity to hydration and reactivity dependent on the length of the triglyceride fatty acid. In order to overcome these problems, it would be important to find out a catalyst, either homogenous or heterogeneous, able to overcome these disadvantages, still affording high triglyceride conversion and triacetin yield.

The simultaneous production of FAME and TAG from vegetable oils has been successfully accomplished in supercritical conditions without catalyst $[6,12]$. Since the reactivity of triglycerides and methyl acetate is not very high without a catalyst, extreme (supercritical) reaction conditions are required to obtain high products yields [6], thus imposing a significant challenge on the actual scalability of the process. Good yields of the FAME-TAG mixtures were obtained at rather high temperatures $\left(350^{\circ} \mathrm{C}\right)$ and pressures $(20 \mathrm{kPa})$ even after reaction parameters optimization by statistical methods [13]. Although FAME production was nearly quantitative, the final yield of the FAME/TAG mixture was lower (about $80 \%$ ) than the theoretical value.
In this work, the simultaneous synthesis of both FAME and glycerol oxygenated derivative, i.e. glycerol esters, from tributyrin in the presence of methyl acetate has been studied in detail. Tributyrin, a butter component, which is the shortest naturally occurring triglyceride besides triacetin, has been chosen as the representative model compound of the triglyceride series which includes the vegetable oils used for biodiesel production. A screening of different catalysts, acids and bases, either homogeneous or heterogeneous, were assayed in order to optimize the reaction time and products yields.

\section{Experimental}

\subsection{Materials}

Reagent grade methyl-acetate, methyl butyrate, tributyrin, triacetin and tetradecane were from Acros Organics (Italy). 1,8Diazo-bicyclo-[5.4.0]undec-7-ene (DBU) and 1,5,7-Triaza-bicyclo [4.4.0]dec-5-ene (TBD) were from Fluka (Switzerland). Potassiumtertbutoxide, acetic acid, sulphuric acid, trifluoromethanesulphonic acid, methanesulphonic acid and acetic anhydride were from Sigma-Aldrich (Italy). Sodium methoxide was freshly prepared for each reaction, by carefully weighting the appropriate amount of sodium metallic, according to the procedure described in the literature [14]. In order to obtain full solubility in methyl acetate, dry powder of sodium methoxide was prepared from sodium $(0.041 \mathrm{~g}$, $1.8 \mathrm{mmol}$ ) and methanol ( $1.58 \mathrm{~g}, 49.3 \mathrm{mmol})$. After $3 \mathrm{~h}$ under vigorous stirring, methanol was evaporated with nitrogen, until a dry fine powder was obtained.

Nafion Sac-13 was from Sigma-Aldrich (Italy). Amberlyst 15 was a generous gift of Rohm and Haas (Italy). Both were washed with methanol and dried under vacuum overnight at $90^{\circ} \mathrm{C}$ before use. According to the producers, Nafion SAC 13 and Amberlyst 15 have 0.14 and $4.7 \mathrm{mmol} \mathrm{equiv}_{\mathrm{H}}{ }^{+} / \mathrm{g}$, respectively (Table 2 ).

Zirconia sulphate (XZO1249, containing $7 \mathrm{wt} \% \mathrm{SO}_{3}$ ) and zirconia tungstate (XZO1251, containing $16 \mathrm{wt} \% \mathrm{WO}_{3}$ ) were a gift from MEL Chemicals (UK). The powders, separated on a $600 \mu \mathrm{m}$ sieve, were calcined at $550^{\circ} \mathrm{C}$ for $5 \mathrm{~h}$ and transferred to the reaction vessel under dry nitrogen atmosphere. Zeolite $\beta$ (CP814E) was purchased from Zeolyst International (The Netherlands). It was calcined at $460^{\circ} \mathrm{C}$ for $5 \mathrm{~h}$ and stored under dry nitrogen atmosphere. The $\mathrm{SiO}_{2} / \mathrm{Al}_{2} \mathrm{O}_{3}$ mole ratio was 20 and the $\mathrm{Al}$ content was $1.6 \mathrm{mmol} / \mathrm{g}$. Acid sites (Table 2) were measured by IR analysis of pyridine absorption at $250^{\circ} \mathrm{C}$ according to the procedure described in the literature [15].

The alkaline form of ETS-10 sample was supplied by Engelhard (Iselin, NJ, USA). Elemental analysis gave $\mathrm{TiO}_{2} 18.5 \%, \mathrm{Na}_{2} \mathrm{O} 12.0 \%$ and $\mathrm{K}_{2} \mathrm{O} 3.9 \%$. ETS-10 is a microporous crystalline material having 12 - and 7-membered ring channels. Its structure is topologically similar to that of zeolite $\beta$. Katalco 59-3, a high porosity sodium aluminate spherical absorbent, was from JM Group (UK). Pural Mg 70, from Sasol Germany GmbH (DE) is a commercial hydrotalcitelike anionic clays $\mathrm{MgO}=71 \% \mathrm{Al}_{2} \mathrm{O}_{3}=29.2 \%$. All these materials were thermally activated for $3 \mathrm{~h}$ as shown in Table 2 .

Mixed oxides samples Mg:Al 3:1 and Mg:Al 3:1 + 10\% Fe were prepared from layered double hydroxides (LDH) hydrotalcites and 
Table 1

Physico-chemical properties of different fuel blendings and standards of allowed quantities in diesel.

\begin{tabular}{|c|c|c|c|c|c|}
\hline Property & Base diesel & Base diesel + 10\% FAME ${ }^{\mathrm{a}}$ & Base diesel + 10\% FAME-TAG ${ }^{\mathrm{b}}$ & Diesel limits EN590 & Methods \\
\hline Density $15^{\circ} \mathrm{C}, \mathrm{kg} / \mathrm{m}^{3}$ & 836.2 & 839.2 & 844.5 & $820-845$ & EN ISO 12185 \\
\hline Cetane number & 53.2 & 53.5 & 53.9 & $\geq 51$ & ASTM D613 \\
\hline Cetane index & 53.8 & 54.5 & 52.1 & $\geq 46$ & ASTM D4737 \\
\hline Flash point $\mathrm{PM},{ }^{\circ} \mathrm{C}$ & 66 & 73.5 & 72.5 & $\geq 55$ & ASTM D93 \\
\hline Kin. viscosity $40^{\circ} \mathrm{C}, \mathrm{mm}^{2} / \mathrm{s}$ & 2.989 & 3.049 & 3.041 & $2.0-4.5$ & ASTM D445 \\
\hline Cloud point, ${ }^{\circ} \mathrm{C}$ & -3.7 & -2.7 & -2.5 & & ASTM D2500 \\
\hline $\mathrm{CFPP}^{\mathrm{C}},{ }^{\circ} \mathrm{C}$ & -3 & -4 & -6 & $-20 /+5$ & EN 116 \\
\hline Copper corrosion, class & $1 \mathrm{~A}$ & $1 \mathrm{~A}$ & $1 \mathrm{~A}$ & Class 1 & ASTM D130 \\
\hline Acidity number, mg KOH/g & 0.05 & 0.07 & 0.07 & & ASTM D974 \\
\hline Distillation $95 \%,{ }^{\circ} \mathrm{C}$ & 357.6 & 352.8 & 355.8 & $\leq 360$ & ASTM D86 \\
\hline
\end{tabular}

a FAME from vegetable oil was certified according to EN14214 specifications. Percentages on volume base.

b FAME and triacetin (TAG) mixture: $81 \%$ and $19 \%$, respectively.

c Cold filter plug point.

were synthesized according to the procedure described in the literature [16]. Hydrotalcite, molar ratio $\mathrm{Mg}: \mathrm{Al} \mathrm{6:1,} \mathrm{was} \mathrm{prepared} \mathrm{by}$ $\mathrm{pH}$ controlled co-precipitation of the corresponding metal nitrate salts $\mathrm{Mg}\left(\mathrm{NO}_{3}\right)_{2} \cdot 6 \mathrm{H}_{2} \mathrm{O}$ (Sigma-Aldrich, Italy) and $\mathrm{Al}\left(\mathrm{NO}_{3}\right)_{3} \cdot 9 \mathrm{H}_{2} \mathrm{O}$ (Sigma-Aldrich, Italy) under low supersaturation. The synthesis was carried out as follows: to $25 \mathrm{ml}$ of distilled water heated at $35^{\circ} \mathrm{C}$ under vigorous stirring, $100 \mathrm{ml}$ of an aqueous mixture of $0.225 \mathrm{~mol}$ $\mathrm{Mg}\left(\mathrm{NO}_{3}\right)_{2} \cdot 6 \mathrm{H}_{2} \mathrm{O}$ and $0.0375 \mathrm{~mol} \mathrm{Al}\left(\mathrm{NO}_{3}\right)_{3} \cdot 9 \mathrm{H}_{2} \mathrm{O}$ was added slowly along with $100 \mathrm{ml}$ of an aqueous solution containing $0.349 \mathrm{~mol}$ $\mathrm{NaOH}$ and $0.067 \mathrm{~mol} \mathrm{Na}_{2} \mathrm{CO}_{3}$. The mixture was maintained at $\mathrm{pH}$ 11 at $35^{\circ} \mathrm{C}$ for $16 \mathrm{~h}$ under stirring. The precipitate was isolated by filtration and washed with deionized water to eliminate the nitrate and alkali metal ions until the washing water was at $\mathrm{pH} 7$. The precipitated hydrotalcite was dried overnight at room temperature. In order to obtain the corresponding $\mathrm{Mg}-\mathrm{Al}$ mixed oxides the sample was calcined at $450^{\circ} \mathrm{C}$ for $5 \mathrm{~h}$.

The chemical composition of the mixed oxides was measured by an inductively coupled plasma (ICP) method, LIBERTY 200-VARIAN spectrometer, after the digestion of the sample with nitric acid. The ICP molar ratio of mixed oxides samples $\mathrm{Mg}: \mathrm{Al} \mathrm{3:1}$ and $\mathrm{Mg}: \mathrm{Al}$ $6: 1$ was 3.72 and 6.61 , respectively. The basicity of the material was estimated by adsorption microcalorimetry using $\mathrm{CO}_{2}$ as probe molecule. A Tian-Calvet flow equipment (Setaram, France) equipped with a volumetric vacuum line was used for microcalorimetric measurements. In Table 2 the total micromole/g sites for adsorption heat $>70 \mathrm{~kJ} / \mathrm{mol}$ of the $\mathrm{Mg}: \mathrm{Al} \mathrm{3:1,} \mathrm{Mg}: \mathrm{Al} \mathrm{6:1}$ and iron doped (10\%) mixed oxide samples are reported.

The surface area and pore volume for all the heterogeneous catalysts screened are presented in Table 2 . The data are those available from the manufacturers or were collected by determining the
$\mathrm{N}_{2}$ adsorption/desorption isotherms at $77 \mathrm{~K}$ with a ThermoquestSorptomatic 1990 instrument.

\subsection{Water content}

Methyl acetate was freshly distilled and stored over calcined $\left(500{ }^{\circ} \mathrm{C}\right.$ for $5 \mathrm{~h}$ ) molecular sieves. Tributyrin was dried on molecular sieves under reduced pressure overnight at $100^{\circ} \mathrm{C}$. The water content of both reagents as assayed by standard Karl-Fischer titration (737 KF Coulometer from Methrohm, Herisau, Switzerland) was $40-50 \mathrm{ppm}$. Potassium tert-butoxide was stored in a closed glass vessel over phosphorous pentoxide. Organic acids were used as purchased without further dehydration.

\subsection{Interesterification reactions}

The reactions in homogeneous conditions were typically carried on in a $20 \mathrm{ml}$ thick-glass screw capped vessel containing tributyrin $(2.3 \mathrm{~g}, 7.6 \mathrm{mmol})$, methyl acetate $(11.2 \mathrm{~g}, 151 \mathrm{mmol})$ and acid (sulphuric, acetic, methanesulphonic and trifluoromethanesulphonic acid) or base (potassium tertbutoxide, sodium methoxide) catalyst (usually $5-10 \mathrm{~mol} / \mathrm{mol} \%$ of tributyrin). The reaction vessel under stirring was immersed in a temperature controlled oil bath. The molar ratio tributyrin:methyl acetate was usually $1: 20$.

The reaction with solid heterogeneous acid and base catalysts was carried on in a $20 \mathrm{ml}$ thick-glass screw capped vessel containing tributyrin $(3.3 \mathrm{~g}, 10.94 \mathrm{mmol})$, methyl acetate $(16.1 \mathrm{~g}$, $217.2 \mathrm{mmol}$ ) and heterogeneous acid or base catalyst (usually $3-5$ mequiv $_{\mathrm{H}}^{+} / \mathrm{mol} \%$ of tributyrin or $5-15 \%(\mathrm{w} / \mathrm{v})$ concentration).

Table 2

Textural and physical characterization of catalysts.

\begin{tabular}{|c|c|c|c|c|c|c|}
\hline & $T_{\mathrm{C}}\left({ }^{\circ} \mathrm{C}\right)$ & $S_{\text {BET }}\left(\mathrm{m}^{2} / \mathrm{g}\right)$ & $V_{\text {pore }}\left(\mathrm{cm}^{3} / \mathrm{g}\right)$ & $d(\mathrm{~nm})$ & mmol equiv/ga & Reference \\
\hline Mixed oxide Mg:Al 3:1 & 450 & 244 & 0.55 & 19 & 0.12 & This work \\
\hline Mixed oxide Mg:Al 6:1 & 450 & 220 & 0.55 & 37 & 0.25 & This work \\
\hline Mixed oxide Mg:Al 3:1 + Fe 10\% & 450 & 239 & 0.64 & 33 & 0.11 & This work \\
\hline ETS-10 & 450 & 380 & 0.15 & $0.5-0.8$ & $0.5^{\mathrm{c}}$ & This work \\
\hline Katalco & 450 & 250 & 0.3 & $2.0-4.7$ & - & JM Group \\
\hline Pural Mg 70 Mg:Al 3:1 & 500 & 203 & 0.22 & 5.2 & - & {$[32]$} \\
\hline Nafion SAC-13 & - & $>200$ & 0.6 & $>10$ & 0.14 & Sigma-Aldrich \\
\hline Amberlyst 15 & - & 53 & 0.4 & $30-50$ & 4.7 & Rhom\&Haas \\
\hline Zirconia $\left(\mathrm{SO}_{3}\right)$ & 550 & $>300$ & 0.3 & - & $0.09^{c}$ & MEL Chemicals \\
\hline Zirconia $\left(\mathrm{WO}_{3}\right)$ & 550 & $>300$ & 0.3 & $3.0^{\mathrm{d}}$ & $0.06^{c}$ & MEL Chemicals \\
\hline Zeolite $\beta$ & 460 & 655 & 0.24 & 0.65 & $0.47^{e}$ & This work \\
\hline
\end{tabular}

$T_{\mathrm{C}}$ : calcination temperatures; $S_{\mathrm{BET}}$ : surface area; $V_{\text {pore }}$ : pore volume; $d$ : pore diameter.

a mmol equiv/g are the acid or base equivalents per $g$ of calcined catalyst.

b $10 \%$ is the concentration of iron salt at the beginning of the synthesis.

c [21].

d [31].

e Brønsted and Lewis acid sites: 0.27 and $0.20 \mathrm{mmol}$ equiv/g, respectively. 
<smiles>C=CCC(=O)OCC(COC(=O)CCCC)OC(=O)CCCC</smiles><smiles>CCCCC(=O)OCC(COC(C)=O)COC(=O)CCCCCCCCC(=O)OC</smiles><smiles>CCCCC(=O)OCC(CCC)COC(C)=O</smiles><smiles>COC(C)=O</smiles><smiles>C=C</smiles><smiles>CCCCC(=O)OCC(COC(C)=O)OC(C)=O</smiles><smiles>CCCCCCCCCCCCC</smiles>

DAG<smiles>CCCCCCC(=O)OCC(COC(C)=O)OC(C)=O</smiles><smiles>COC(C)=O</smiles><smiles>C=C</smiles><smiles>CC(=O)OCC(COC(C)=O)OC(C)=O</smiles><smiles>CCCCCCCCCCCCCC</smiles>

TAG

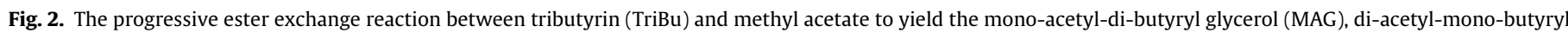
glycerol (DAG), triacetyl glycerol (TAG, triacetin) and butyrate methyl ester (BuMe).

The reaction was heated under vigorous stirring in a temperature controlled oil bath.

The products concentrations as a function of time were measured by preparing a series of glass vessels carefully loaded by weight with the same amount of reagents and catalyst. All the vessels were simultaneously immersed in a thermostated oil bath at a given temperature. Each vessel was then separately withdrawn at regular time intervals. After sudden cooling in an ice bath, the whole content was analyzed by GC as described below.

\subsection{Products analysis}

Products yields, expressed as percentages, were calculated in the following way. Tributyrin (TriBu) conversions, i.e. percentage of TriBu reacted with respect to the initial concentration of TriBu, are based on gaschromatographic quantitative analysis.

The moles of reacted TriBu, [TriBu], are distributed among the intermediates (mono-acetyl-di-butyryl glycerol, MAG, and di-acetyl-mono-butyryl glycerol, DAG) and final products (TAG), according to the following conservation equations (square brackets are molar concentrations):

$[\text { TriBu }]_{g l y}=[\mathrm{MAG}]+[\mathrm{DAG}]+[\mathrm{TAG}]$

$3 \times[\text { TriBu }]_{b u t}=2[\mathrm{MAG}]+[\mathrm{DAG}]+[\mathrm{BuMe}]$

where the subscript ' $g l y$ ' and 'but' stand for glycerol moiety and butyl group, respectively. Selectivity was calculated by using the following equations,

$\operatorname{MAG}(\mathrm{mol} \%)=\frac{[\mathrm{MAG}]}{[\mathrm{MAG}]+[\mathrm{DAG}]+[\mathrm{TAG}]} \times 100$
$\operatorname{DAG}(\mathrm{mol} \%)=\frac{[\mathrm{DAG}]}{[\mathrm{MAG}]+[\mathrm{DAG}]+[\mathrm{TAG}]} \times 100$
$\mathrm{TAG}(\mathrm{mol} \%)=\frac{[\mathrm{TAG}]}{[\mathrm{MAG}]+[\mathrm{DAG}]+[\mathrm{TAG}]} \times 100$

MAG, DAG and TAG percentages in Tables 3-6 are correlated to the concentration of TriBu by means of Eq. (1), which expresses the mass balance of the glycerol moiety. Their sum has to be equal, within the experimental uncertainty, to the value of TriBu conversion listed in the same Tables. BuMe percentages are calculated with respect to $3 \times$ TriBu and have to fulfil Eq. (2), the mass balance of the butyl group. Therefore, BuMe molar yields, corrected by the number of butyl chains, are expressed as percentages within a $0-100 \%$ scale and, although do not sum up directly to the other products values (i.e. MAG, DAG and TAG) shown in Tables 3-6, nevertheless give a direct insight of the product yield. The highest observed experimental uncertainty on the mass balances (1) and (2) was less than $\pm 7 \%$.

\subsubsection{Analytical methods}

The analysis of the reaction mixture was carried on with a Carlo Erba 8000 Top (Italy) GC instrument equipped with a split-splitless injection system. A Thermo TR-5 $(30 \mathrm{~m} \times 0.25 \mathrm{~mm}$, film thickness $0.25 \mu \mathrm{m}$ ) capillary column was used for the analysis. The temperatures of the injector and detector (FID) were set at $270^{\circ} \mathrm{C}$ and $360^{\circ} \mathrm{C}$, respectively. The column temperature was kept at $80^{\circ} \mathrm{C}$ for $4 \mathrm{~min}$, raised to $280^{\circ} \mathrm{C}$ at $10^{\circ} \mathrm{C} \mathrm{min}^{-1}$ and maintained at this temperature for $5 \mathrm{~min}$. Tributyrin (TriBu), butyrate methyl ester (BuMe) and triacetin (TAG) were quantitatively determined by using a reference internal standard (tetradecane) and suitable calibration curves. The concentration of acetylated intermediates (MAG and DAG) was determined by using empirical calibration coefficients estimated from triacetin and tributyrin experimental instrumental response as a function of concentration. 
Table 3

Interesterification between tributyrin and methyl acetate in the presence of homogeneous acid catalysts.

\begin{tabular}{|c|c|c|c|c|c|c|}
\hline Catalyst $^{\mathrm{a}}$ & $T,{ }^{\circ} \mathrm{C}$ & $\mathrm{TriBu}^{\mathrm{b}}, \%$ & $\mathrm{MAG}^{\mathrm{c}}, \%$ & $\mathrm{DAG}^{\mathrm{c}}, \%$ & $\mathrm{TAG}^{\mathrm{c}}, \%$ & $\mathrm{BuMe}^{\mathrm{d}}, \%$ \\
\hline Methanesulphonic acide & 130 & 9 & 8 & 1 & 0 & 4 \\
\hline Sulphuric acid & 130 & 50 & 10 & 39 & 1 & 29 \\
\hline Trifluoro-acetic acid & 130 & 3 & 2 & 0 & 0 & 2 \\
\hline Trifluoro-MS acid & 130 & 99 & 4 & 27 & 66 & 93 \\
\hline Trifluoro-MS acid & 140 & 99 & 4 & 24 & 69 & 92 \\
\hline Trifluoro-MS acid & 160 & 94 & 9 & 25 & 59 & 88 \\
\hline Trifluoro-MS acid + acetic acid & 130 & 99 & 5 & 25 & 69 & 91 \\
\hline Trifluoro-MS acid + acetic anhydride & 130 & 99 & 4 & 19 & 78 & 92 \\
\hline
\end{tabular}

Table 4

Interesterification between tributyrin and methyl acetate in the presence of heterogeneous acid catalysts.

\begin{tabular}{|c|c|c|c|c|c|c|}
\hline Catalyst & $T,{ }^{\circ} \mathrm{C}$ & TriBu, \% & MAG, \% & DAG, \% & TAG, $\%$ & BuMe, \% \\
\hline Nafion SAC13 & 80 & 7 & 6 & 1 & 0 & 4 \\
\hline Nafion SAC13 & 130 & 98 & 8 & 26 & 60 & 83 \\
\hline Nafion SAC13 ${ }^{\mathrm{a}}$ & 160 & 88 & 22 & 36 & 29 & 62 \\
\hline Amberlyst 15 & 120 & 9 & 7 & 2 & 0 & 4 \\
\hline Zirconia $\left(\mathrm{SO}_{3}\right)$ & 140 & 72 & 36 & 24 & 11 & 42 \\
\hline Zirconia $\left(\mathrm{WO}_{3}\right)$ & 140 & 14 & 10 & 2 & 1 & 8 \\
\hline Zeolite $\beta$ & 130 & 36 & 29 & 7 & 0 & 13 \\
\hline
\end{tabular}

TriBu: tributyrin conversion. MAG, DAG, TAG and BuMe yields as in Table 3. Reaction time: $20 \mathrm{~h}$.

a $8 \mathrm{~h}$.

\subsubsection{Fuel properties}

The physico-chemical properties of the fuel blends were assayed according to international standard methods (Table 1) in the laboratories of the Research Center of Eni S.p.A., R\&M Division, San Donato Milanese, Milan (Italy). FAME $\left(C_{12}-C_{22}\right)$ was from vegetable oil and it was certified according to EN14214 specifications.

\section{Results and discussion}

\subsection{Screening of catalysts}

The interesterification between tributyrin (TriBu) and methyl acetate (AcOMe) is composed of three reversible consecutive steps as shown schematically in Fig. 2. The overall net reaction is based on the interchange of acyl groups and, as a first approximation and regardless the catalytic mechanism, relies upon the concurrent availability of both a nucleophilic methoxide and an electrophilic acetyl groups, both formally obtained from AcOMe. As shown in Fig. 2, for each acylation step $1 \mathrm{~mol}$ of fatty acid methyl ester, BuMe, is synthesized until triacetin (TAG), the fully acetylated glycerol, is formed.

Due to the reversible character of the reactions, complete conversion of TriBu does not imply a quantitative yield of TAG. As a matter of fact the partially acetylated intermediates (MAG and DAG) tend to accumulate to some extent. This is not surprising because, as observed in the case of the esterification of glycerol with acetic acid, the reaction between the third acyl group and the di-acetyl glycerine has an equilibrium constant significantly lower than the first acylation step [7,17].

The aim of this work is to find a suitable catalyst, either acid or base, able to shift the reaction as much as possible towards the end product, TAG, optimizing in the same time the yield of FAME. For this purpose, a screening of acid and base catalysts, either soluble or heterogeneously dispersed, was performed.

\subsection{Homogenous acid catalysis}

The results of the screening for an efficient homogenous acid catalyst are presented in Table 3. The best yields were obtained with trifluoromethanesulphonic acid (trifluoro-MS acid in Table 3), which afforded an almost quantitative yield of methyl butyrate and $66 \%$ yield of triacetin (TAG) at $130^{\circ} \mathrm{C}$. TriBu conversion and products yields were roughly proportional to the acidity strength of the catalyst, defined by its acid dissociation constant [18], following the series acetic acid $<$ methanesulphonic acid $<$ sulphuric acid «trifluoromethanesulphonic acid. According to the proposed

Table 5

Interesterification between tributyrin and methyl acetate in the presence of homogeneous base catalysts.

\begin{tabular}{|c|c|c|c|c|c|c|c|}
\hline Catalyst & Time, h & $T,{ }^{\circ} \mathrm{C}$ & TriBu, \% & MAG, \% & DAG, $\%$ & TAG, \% & BuMe, \% \\
\hline Na methoxide & 0.1 & 80 & 98 & 5 & 30 & 63 & 89 \\
\hline Na methoxide & 0.2 & 60 & 99 & 4 & 25 & 68 & 93 \\
\hline $\mathrm{K} t$-butoxide & 0.2 & 80 & 96 & 8 & 24 & 65 & 90 \\
\hline $\mathrm{K} t$-butoxide & 0.2 & 60 & 98 & 6 & 23 & 66 & 92 \\
\hline TBD & 5 & 80 & 80 & 31 & 43 & 7 & 36 \\
\hline TBD & 5 & 140 & 72 & 30 & 38 & 7 & 32 \\
\hline DBU & 5 & 80 & 8 & 5 & 3 & 0 & 4 \\
\hline DBU & 5 & 140 & 17 & 10 & 6 & 0 & 8 \\
\hline $\mathrm{DBU}+\mathrm{MeOH} 30 \%$ & 5 & 140 & 16 & 12 & 3 & 1 & 7 \\
\hline
\end{tabular}

TriBu: tributyrin conversion. MAG, DAG, TAG and BuMe yields as in Table 3. Catalyst concentration: $5 \mathrm{~mol} / \mathrm{mol} \% \mathrm{TriBu}$. MeOH: $30 \mathrm{~mol} / \mathrm{mol} \% \mathrm{TriBu}$. 
Table 6

Interesterification between tributyrin and methyl acetate in the presence of heterogeneous base catalysts.

\begin{tabular}{|c|c|c|c|c|c|c|c|}
\hline Catalyst & Catalyst, \% (w/v) & $T,{ }^{\circ} \mathrm{C}$ & TriBu, \% & MAG, \% & DAG, \% & TAG, \% & BuMe, \% \\
\hline Mixed oxide MgAl 3:1 & 5 & 80 & 5 & 4 & 1 & 0 & 2 \\
\hline Mixed oxide MgAl 3:1 & 5 & 140 & 20 & 17 & 2 & 0 & 9 \\
\hline Mixed oxide MgAl 6:1 & 5 & 140 & 25 & 22 & 3 & 0 & 11 \\
\hline Mixed oxide MgAl 3:1 & 15 & 140 & 45 & 30 & 10 & 4 & 24 \\
\hline Mixed oxide $\mathrm{MgAl} 3: 1+\mathrm{Fe} 10 \%^{\mathrm{a}}$ & 15 & 140 & 39 & 27 & 8 & 3 & 22 \\
\hline ETS-10 & 10 & 80 & 4 & 3 & 1 & 0 & 2 \\
\hline Katalco & 10 & 80 & 3 & 2 & 1 & 0 & 2 \\
\hline Pural Mg 70 & 10 & 80 & 19 & 9 & 10 & 1 & 9 \\
\hline
\end{tabular}

TriBu: tributyrin conversion. MAG, DAG, TAG and BuMe yields as in Table 3. Reaction time: $8 \mathrm{~h}$.

a $10 \%$ is the iron salt concentration at the beginning of the synthesis.

reaction mechanism of the interesterification of triglycerides with methanol (a nucleophilic acylic substitution), a key step in acid catalysis is the interaction between the acid proton and the carbonylic oxygen of the ester [19]. Therefore, it is reasonable to assume that the stronger the acid strength, the more effective the degree of the interaction with the carbonyl oxygen ('protonation'), the more effective the products accumulation, in agreement with the experimental results.

TAG concentration reached a value of $66 \%$ and $69 \%$ at $130{ }^{\circ} \mathrm{C}$ and $140^{\circ} \mathrm{C}$, respectively. These numbers approximately indicate that only two/third of the possible acetyl groups were incorporated. Even an increase of the catalyst concentration from 5 to $10 \mathrm{~mol} / \mathrm{mol} \%$ (data not shown) did not change significantly the final yields. On the other hand, it should be noted that in the conventional esterification of glycerol with acetic acid, the selectivity towards TAG is even lower, being comprised between $30 \%$ and $40 \%[2,8]$. Complete DAG conversion into TAG is prevented because these types of esterification may be considered a typical equilibrium limited reactions [20].

The time dependence of the products yields and TriBu conversion at $130^{\circ} \mathrm{C}$ in the presence of trifluoro-methanesulphonic acid as catalyst is shown in Fig. 3. As it can be seen, tributyrin conversion is complete, whereas MAG and DAG intermediates, after the initial accumulation, tend to decrease levelling asymptotically off to a constant value. As a consequence, TAG concentration increases until a plateau value, not significantly improved after longer reac-

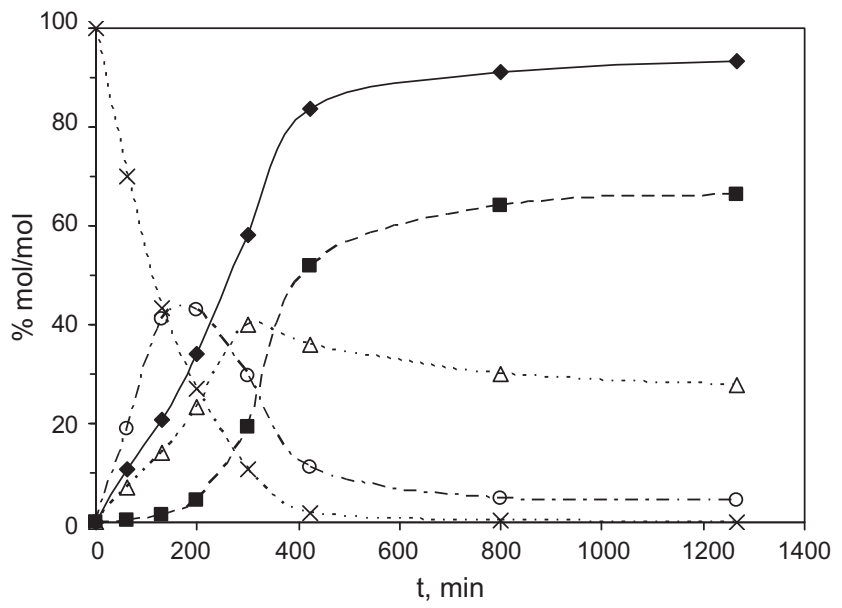

$\longrightarrow$ BuMe --- TAG $\cdots \Delta \cdot$ DAG $-\bullet \cdot-$ MAG $\cdots \times \cdots$ TriBu

Fig. 3. Time dependence of reactant and product concentrations expressed as $\mathrm{mol} / \mathrm{mol}$ percentages. Homogenous acid catalysis at $130^{\circ} \mathrm{C}$. Tributyrin $1.1 \mathrm{~g}$ (3.75 mmol), methyl acetate $5.5 \mathrm{~g}$ (74 mmol). Catalyst: trifluoro-methanesulphonic acid $0.028 \mathrm{~g}(0.18 \mathrm{mmol})$. TriBu: percentage of the initial tributyrin concentration. MAG, DAG and TAG: percentages of the reacted TriBu. BuMe: percentages of 3 times the initial TriBu concentration (see Eq. (2), Fig. 1). Lines are not fitting curves; they are drawn for clarity sake. tion time, is reached. The final products concentrations are those reported in Table 3.

In our experimental conditions, different strategies were adopted to increase TAG yield, without, however, significant results. For instance, an increase in temperature did not induce a significant improvement of the yield, which actually decreases at $160^{\circ} \mathrm{C}$. This is probably due to the presence of side reactions, such as acid induced dehydration of glycerol moiety, which becomes significant at high temperature and lead to unbalanced products yields. Moreover, as shown in Table 3, the addition of acetic acid to cover the remaining $30 \%$ of the acetyl molecules need for complete acylation of DAG did not improve the yield, suggesting that, in order to shift the equilibrium condition, a much higher concentration would be needed.

A possible way to overcome the equilibrium limitation is the presence of a side independent reaction able to interact directly with DAG. This may be accomplished by the addition of strong acylation agents, such as anhydrides. As a matter of fact, the addition of acetic anhydride ( $30 \mathrm{~mol} / \mathrm{mol} \%$ of TriBu) indeed caused a significant improvement of the TAG yield, from $66 \%$ up to $78 \%$ at $130^{\circ} \mathrm{C}$. These effects were not further investigated because a complete interconversion of the esters without further addition of other reactants is a more appealing option from process development point of view.

The influence of water on the reaction was significant. It was necessary to keep the overall water content below 100 ppm. Progressive deviation of the product mass balance was observed as a function of water content, which, if increased up to several hundreds ppm, induced the formation of a cloudy reaction mixture. Mass analysis of the dispersed phase showed the presence of hydrolysis products containing free glycerol $-\mathrm{OH}$ group.

\subsection{Heterogeneous acid catalysis}

The results obtained in the presence of solid acid catalysts are presented in Table 4. Zirconias as well as zeolite $\beta$ are defined 'strong acid' catalysts by the producers and indeed they were able to convert TriBu to some extent into different glycerol derivatives. The highest TAG yield was $11 \%$, obtained in the presence of sulphated zirconia. However, the performance of these catalysts was limited as pointed out by the low degree of TriBu conversion.

Both zirconias and zeolite $\beta$ showed sufficient acid site strength to catalyze biodiesel-forming transesterification with methanol, although with different degrees of efficiency. The highest yields were obtained with sulphated zirconia (although much less efficiently than sulphuric acid) and the lowest ones with zeolite $\beta$ [21]. However, their average pore diameters (Table 2) are different and consequently tributyrin accessibility to pore cavities varies significantly. The fully extended tributyrin molecule is $1.8 \mathrm{~nm}$ long (including Van der Walls radii, as calculated by standard molecular modelling techniques) and pore accessibility is hampered for zeolite $\beta$ (pore diameter: ca. $0.65 \mathrm{~nm}$ ). Therefore, poor catalytic efficiency may be related to the strength of the zeolite acid sites, i.e. 
$\mathrm{Al}(\mathrm{O}-\mathrm{H}) \mathrm{Si}$, of the crystal surface which is a structural property of the material [22], sufficient to catalyze the transesterification with methanol [21], but not enough to afford reasonable yields in the double ester exchange interesterification.

Amberlyst 15 is a synthetic resin containing sulphonic groups at a concentration (weight base) higher than any other acid catalysts (Table 2). Although active in the conventional transesterification with methanol to obtain FAME in spite of the low surface area [23], it was not able to significantly catalyzed the interesterification reaction as shown in Table 4 . This result was somehow expected since the corresponding acid compound, methanesulphonic acid, already expressed a low activity in homogeneous conditions (Table 3 ).

The best results were obtained with Nafion SAC-13, a silica based material containing polymeric perfluorinated chains terminated with sulphonic groups: it is the heterogeneous equivalent of the trifluoromethanesulphonic acid. At $130^{\circ} \mathrm{C}$ the conversion of TriBu was almost quantitative, BuMe (FAME) yield was $83 \%$, whereas TAG selectivity was $60 \%$. The time dependence of the products formation was similar to those shown in Fig. 3 in homogeneous conditions with trifluoro-methanesulphonic acid as catalyst (data not shown). These final yields, however, were slightly lower than those obtained in solution (see Tables 3 and 4) as expected for a heterogeneous catalyst. As in the case of homogeneous catalysis, the increase of the temperature up to $160^{\circ} \mathrm{C}$ had a negative influence on the final product distribution, decreasing the overall yields and unbalancing the mass equations (1) and (2). Careful studies on Nafion stability lead to the conclusion that the structural integrity of the material was conserved after repeated recycling at $130^{\circ} \mathrm{C}$ (no leaching of the $-\mathrm{SO}_{3} \mathrm{H}$ groups was observed) and that the partially reversible loss of the activity was due to the poisoning adsorption of by-products on the catalytic sites [24].

Fluoro-sulphonic acids supported on porous silica, as in Nafion SAC-13 composite, have been successfully studied as an alternative those methods that exploit isomorphous lattice substitution to enhance intrinsic acidity. As a consequence, the efficiency of such materials rely not only on the strengths of acid sites but also on the better accessibility of acid sites, enhancing their specific activity as catalyst, even with respect to synthetic resins, i.e. the Amberlyst family, as indeed has been observed experimentally for different reactions [25,26]. Moreover, it has been reported that this composite is both chemically (as expected due to the fluorocarbon nature of the backbone) and thermally stable up to $280^{\circ} \mathrm{C}$, at which temperature the sulphonic acid groups begin to decompose [25,27].

As mentioned above, the acidity of Nafion is not a structural property of the silica material by itself. It is related to the tethered pendant fluorosulphonic side chains which are probably long enough to react similarly as free molecules in solution, as indeed it has been confirmed from kinetic studies on triacetin transesterification [27]. It was concluded that the kinetic mechanism and the reaction activation energy of triacetin transesterification with methanol catalyzed by Nafion are quite similar to those when the catalyst is sulphuric acid in homogenous conditions. This may explain the similarity of the results between Nafion and trifluoromethanesulphonic acid.

\subsection{Homogenous base catalysis}

The reaction between TriBu and methyl acetate catalyzed by different base catalysts in homogeneous conditions are listed in Table 5. Both sodium methoxide and potassium tert-butoxide are soluble in methyl acetate providing that the water is strictly minimized in the reaction media. As it can be seen, in the presence of sodium methoxide fully conversion of TriBu can be achieved within few minutes, even at $60^{\circ} \mathrm{C}$. The selectivity towards TAG reaches $68 \%$, which could not be improved even by adding fresh catalyst to the reaction.

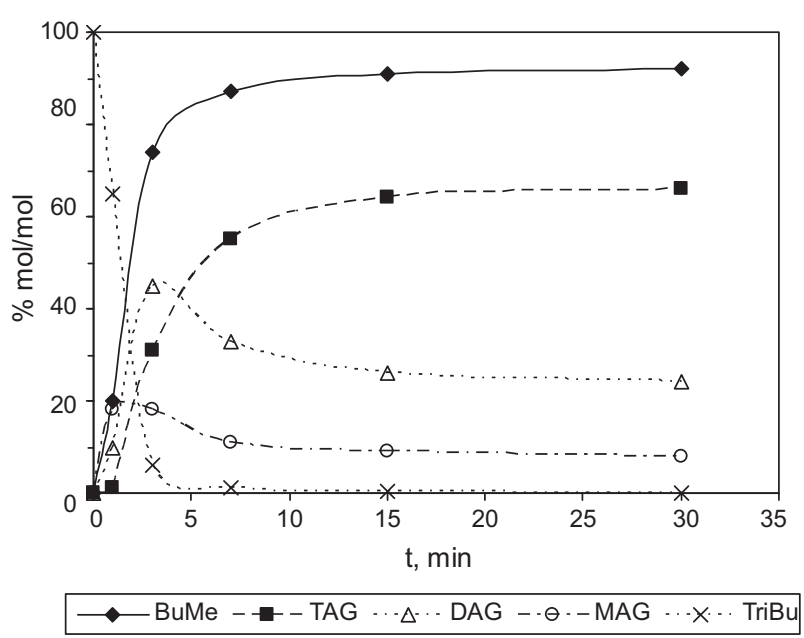

Fig. 4. Time dependence of reactant and product concentrations expressed as $\mathrm{mol} / \mathrm{mol}$ percentages. Homogenous base catalysis at $60^{\circ} \mathrm{C}$. Tributyrin $1.1 \mathrm{~g}$ $(3.75 \mathrm{mmol})$, methyl acetate $5.5 \mathrm{~g}(74 \mathrm{mmol})$. Catalyst: K-tertbutoxide $0.023 \mathrm{~g}$ $(0.205 \mathrm{mmol})$. TriBu: percentage of the initial tributyrin concentration. MAG, DAG and TAG: percentages of the reacted TriBu. BuMe: percentages of 3 times the initial TriBu concentration (see Eq. (2), Fig. 1). Lines are not fitting curves; they are drawn for clarity sake.

The evolution of the products concentrations (expressed as percentages) at $60^{\circ}$ in the case of potassium-tertbutoxide is presented in Fig. 4 as a function of time (the final values are also reported in Table 5). After a rapid evolution of TAG and concurrent decrease of the intermediates, products concentrations level off to an almost constant value. The yields were similar to those obtained in acid catalysis (see Fig. 3, for example), suggesting that the consecutive reaction steps are partially reversible and that a thermodynamic limit (equilibrium condition), independent of the nature of the catalyst, is probably responsible for the missed yield improvement, in spite of the faster reaction rates.

The efficient catalytic activity of these alkoxides may be explained on the basis of the reaction mechanism proposed for the base-catalyzed transesterification of vegetable oils with methanol [19]. The reaction is initiated by a nucleophilic attack of the alkoxide ion at the carbonyl group of the triglyceride, followed by the release of the alkyl ester (BuMe) and the corresponding anion of the diglyceride which brings forth the reaction. According to this mechanism, the catalyst readily reacts because it behaves as a strong nucleophile [28].

The results obtained with potassium tert-butoxide are similar to those observed with sodium methoxide. Although tert-butoxide ion is probably a nucleophile weaker than methoxide ion because of steric hindrance effects, its counter ion, readily displaceable because larger than sodium, could compensate this effect. In fact, it has been observed that the rate of ester interchange reaction (ester exchange) is indeed exponentially related to the atomic radius of the tert-butoxide counterions [23]. As a matter of fact, K-tertbutoxide is a catalyst almost as efficient as sodium methoxide, affording the same conversion and yields, within few more minutes, almost independently of the temperature (Table 5).

TBD is a soluble guanidine-like (tri-aza) bi-cycloamine whose basicity is about 45 higher than DBU, a bi-cyclo di-azoamine [29]. Although TBD is a strong base, it is not able to catalyze efficiently the conversion of TriBu which is not higher than $80 \%$. The selectivity towards TAG is as low as $7 \%$, which is not improved by raising the temperature of even $60^{\circ} \mathrm{C}$. It is probable that, unlike in the case of the transesterification reaction with methanol to prepare FAME where indeed it behaves as a strong base [29], in our ester exchange reactions TBD does not behave as a strong nucleophile probably because of hindrance effects. As a base, DBU is similar but weaker 
than TBD and consequently it has a lower reactivity. The addition of $\mathrm{MeOH}$ did not improve the DBU performance. This is a surprising result if one considers that the catalytic active species, the methoxide ion, should be easily derived from methanol in the presence of a strong base.

\subsection{Heterogeneous base catalysis}

The results obtained in the presence of various basic heterogeneous catalysts are presented in Table 6 . Hydrotalcites are double layered $\mathrm{Mg}^{2+} / \mathrm{Al}^{3+}$ hydroxides whose regular spatial arrangement is lost during calcination at high temperatures. After thermal treatment, which induces the evolution of $\mathrm{H}_{2} \mathrm{O}$ and $\mathrm{CO}_{2}$, a porous amorphous mixed oxide is formed. This material has been successfully used to catalyze the transesterification of vegetable oil with methanol [16]. The intrinsic basicity of the oxide surface may be tuneable by changing the $\mathrm{Mg} / \mathrm{Al}$ ratio. As shown in Table 2, the increase of the $\mathrm{Mg} / \mathrm{Al}$ ratio induced a concurrent increase of the base sites (determined by $\mathrm{CO}_{2}$ adsorption calorimetry). Unfortunately, this did not afford a parallel significant increase of the catalytic activity as suggested by the missed detection of TAG formation.

It was suggested that enhancement of the transesterification catalytic activity of the mixed oxide was apparently improved after the frame insertion of $\mathrm{Fe}^{3+}$ ion due to the increase of the active site basicity (results based on colorimetric evidences) [16]. Therefore, mixed oxides containing $\mathrm{Fe}^{3+}$ ion were prepared with a similar synthesis protocol and characterized by standard XRD and ICP surface analysis that showed the correct structural insertion of the iron (data not shown). The properties of the iron doped oxides are presented in Table 2. The enrichment of the mixed oxide with $\mathrm{Fe}^{3+}$ ion did not alter significantly surface area, porosity and base sites concentration (as assessed by adsorption calorimetry).

As shown in Table 6, the mixed oxide containing a $\mathrm{Mg}-\mathrm{Al}$ ratio of $3: 1$ is almost inactive at $80^{\circ} \mathrm{C}$ and slightly active at $140^{\circ} \mathrm{C}$. A further enhancement of the conversion was observed by increasing the catalyst concentration up to $15 \%(\mathrm{w} / \mathrm{v})$, suggesting that the distribution and concentration of the actual active sites per unit of oxide surface plays a relevant role on the overall catalytic activity. On the other hand, long reaction times ( $20 \mathrm{~h}$, data not shown) did not change the conversion and distribution of the intermediates. The increase of the $\mathrm{Mg} / \mathrm{Al}$ ratio (up to 6:1) and the insertion of $\mathrm{Fe}^{3+}$ ions did not alter significantly the results obtained with the mixed oxide at $15 \%(\mathrm{w} / \mathrm{v})$ concentration.

The commercial hydrotalcite Pural Mg $70(\mathrm{Mg} / \mathrm{Al}$ 3:1) calcined to the corresponding oxides showed an activity even lower than that observed with the other oxides at the same Mg-Al molar ratio. Other basic catalysts, such as titanium-silicalite ETS-10 and sodium aluminate Katalco, although efficient in the transesterification reactions [29], were almost inactive. It should be noted that, unlike ETS-10, Katalco and Pural oxides have average pore diameters that should not significantly limited the accessibility of the tributyrin molecule inside the pores (Table 2).

The activity of these heterogeneous base catalysts is significantly lower than that observed in homogenous conditions. A possible explanation may be related to the intrinsic basicity strength of the material surface which, although enough to catalyze other transesterification reactions, may not sufficient to carry on the ester exchange reaction. On the other hand, the dependence on the concentration of the activity (see Table 6) may suggest that the activity also depends critically on the amount and distribution of the catalytic sites and/or on the surface properties (porosity) of the material. As a matter of fact, in heterogeneous catalysis the interaction between the incoming reactants and the surface active sites is a critical prerequisite for the reaction. Kinetic studies of the transesterification mechanism in the presence of strong base sites suggested that the reacting molecules (which correspond to two esters in our case) have to adsorb on closely neighbouring free reactive sites. Therefore, a reasonable hypothesis, although based on evidences not yet fully established, is that the surface-mediated reaction step between two adsorbed species, more the adsorption of a single species from solution, as in the case of acid catalysis [27], may become the rate determining step $[26,30]$. This implies that effective catalysis critically could depend on geometric and spatial distribution of the surface catalytic sites other than on the basicity strength of the metal oxides.

\section{Conclusions}

The double ester exchange between tributyrin, a model triglyceride, and methyl acetate has been carried out in the presence of either acid or basic catalysts. Base catalysis is characterized by fast reaction rates (few minutes) and moderate temperature requirement $\left(60-80^{\circ} \mathrm{C}\right)$, whereas acid catalysis achieves similar yields in longer reaction time (several hours) and at higher temperature $\left(130-140^{\circ} \mathrm{C}\right)$. These results are similar to those obtained in the case of transesterification of vegetable oils with methanol [19].

Interestingly, under optimized conditions, both types of catalysts yielded a similar amount of reaction products, reaching the same final TGA selectivity of about $70 \%$ even in those cases in which a quantitative conversion of the tributyrin was observed. This implies that the third acetylation step from DAG to form TAG did not go to completion with either type of catalysts. In order to achieve a complete conversion is probably necessary to consider adding a side reaction able to force the equilibrium towards the end product, TAG.

The weight percent composition of the final products mixture is: BuMe $55 \%$, TAG $28 \%$, DAG $15 \%$, MAG $2 \%$, TriBu $0 \%$, out of which only MAG ( $2 \%$ ) may be considered a truly unwanted impurity. The two main products add up to more than $80 \%$ (up to $98 \%$ including DAG). This mixture can be taken into consideration as a component of fossil fuels blends (Table 1 ) if a long fatty acid chain triglyceride (a vegetable oil) were used instead of tributyrin, a triglyceride with a very short chain fatty acid. The study of this reaction by using vegetable oils as substrates could be a further step forward in the search of suitable processes for the synthesis of green diesel components without constrained glycerol accumulation as in the case of the traditional biodiesel synthesis.

\section{Acknowledgments}

Dr. R. Buzzoni is gratefully acknowledged for the synthesis of doped mixed oxides and for providing fully characterized samples of the heterogeneous catalysts. Dr. Daniela Meloni and Franca Sini (Department of Chemical Sciences, University of Cagliari, Italy) are specially acknowledged for the synthesis of mixed oxides at different molar ratios and for the carefully surface area and microcalorimetric measurements, respectively. E.M. Usai thanks the Regione Autonoma della Sardegna for financial support through PO Sardegna FSE 2007-2013, L.R. 7/2007 "Promozione della ricerca scientifica e dell'innovazione tecnologica in Sardegna”.

\section{References}

[1] C.-H. Zhou, J.N. Beltramini, Y.-X. Fan, G.Q. Lu, Chem. Soc. Rev. 37 (2008) 527-549.

[2] J.A. Melero, R. van Grieken, G. Morales, M. Paniagua, Energy Fuels 21 (2007) $1782-1791$.

[3] D. Fabbri, V. Bevoni, M. Notari, F. Rivetti, Fuel 86 (2007) 690-697.

[4] K. Klepáčová, D. Mravec, M. Bajus, App. Catal. A: Gen. 294 (2005) 141-147.

[5] E. García, M. Laca, E. Pérez, A. Garrido, J. Peinado, Energy Fuels 22 (2008) 4274-4280.

[6] S. Saka, Y. Isayama, Fuel 88 (2009) 1307-1313.

[7] D. Gelosa, M. Ramaioli, G. Valente, M. Morbidelli, Ind. Eng. Chem. Res. 42 (2003) 6536-6544. 
[8] X. Liao, Y. Zhu, S.-G. Wang, Y. Li, Fuel Process. Technol. 90 (2009) 988993.

[9] D. Bianchi, E. Battistel, DGMK-Conference "Future Feedstocks for Fuels and Chemicals", Berlin, Germany, September 29-October 1, 2008.

[10] W. Du, Y. Xu, D. Liu, J. Zeng, J. Mol. Catal. B: Enzyme 30 (2004) 125-129.

11] Y. Huang, Y. Yaa, Z. Naturforsch. C: Biosci. 63 (2008) 297-302.

[12] A. Demirbas, Bioresour. Technol. 99 (2008) 1125-1130.

[13] K.T. Tan, K.T. Lee, A.R. Mohamed, Bioresour. Technol. 101 (2010) 965-969.

[14] B. Sreenivasan, J. Am. Oil Chem. Soc. 55 (1978) 796-805.

[15] C.A. Emeis, J. Catal. 141 (1993) 347-354.

[16] G.S. Macala, A.W. Robertson, C.L. Johnson, Z.B. Day, R.S. Lewis, M.G. White, A.V. Iretskii, P.C. Ford, Catal. Lett. 122 (2008) 205-209.

[17] M.-I. Galan, J. Bonet, R. Sire, J.-M. Reneaume, A.E. Pleşu, Bioresour. Technol. 100 (2009) 3775-3778

[18] http://evans.harvard.edu/pdf/evans_pKa_table.pdf.

[19] E. Lotero, Y. Liu, D.E. Lopez, K. Suwannakarn, D.A. Bruce, J.G. Goodwin Jr., Ind. Eng. Chem. Res. 44 (2005) 5353-5363.
[20] O. de la Iglesia, R. Mallada, M. Menendez, J. Coronas, Chem. Eng. J. 131 (2007) 35-39.

[21] D.E. Lopez, J.G. Goodwin Jr., D.A. Bruce, E. Lotero, Appl. Catal. A: Gen. 295 (2005) 97-105.

[22] A. Zecchina, C. Lamberti, S. Bordiga, Catal. Today 41 (1998) 169-177.

[23] M.G. Stanton, M.R. Gagné, J. Am. Chem. Soc. 119 (1997) 5075-5076.

[24] K. Ngaosuwan, E. Lotero, K. Suwannakarn, J.G. Goodwin Jr., P. Praserthdam, Ind. Eng. Chem. Res. 48 (2009) 4757-4767.

[25] M.A. Harmer, Q. Sun, App. Catal. A: Gen. 221 (2001) 45-62.

[26] H. Hattori, M. Shima, H. Kabashima, Stud. Surf. Sci. Catal. 130 (2000)3507-3512.

[27] D.E. Lopez, J.G. Goodwin Jr., D.A. Bruce, J. Catal. 245 (2007) 381-391.

[28] J.W.E. Coenen, Rev. Fr. Corps Gras 21 (1974) 403-413.

[29] U. Schuchardt, R. Sercheli, R.M. Vargas, J. Braz. Chem. Soc. 9 (1998) 199-210.

[30] T.F. Dossin, M.-F. Reyniers, G.B. Marin, Appl. Catal. B: Environ. 61 (2006) 35-45.

[31] R.A. Boyse, E.I. Ko, App. Catal. A: Gen. 177 (1999) L131-L137.

[32] H.A. Prescott, Z.-J. Li, E. Kemnitz, A. Trunschke, J. Deutsch, H. Lieske, A. Auroux, J. Catal. 234 (2005) 119-130. 